\title{
Improved Method for Measurement of Renin Activity in Human Plasma
}

\author{
Yukio Miura \\ Department of Internal Medicine (Prof. T. Torikai), \\ Tohoku University School of Medicine, Sendai
}

\begin{abstract}
A simple and sensitive method for the measurement of plasma renin activity is described. The method consists of prolonged incubation (16 hours) of $2.0-3.0$ $\mathrm{ml}$ of plasma at $37.5^{\circ} \mathrm{C}, \mathrm{pH} 5.5$, with small amounts of both ethylenediamine tetraacetic acid and diisopropyl-fluorophosphate, purification of produced angiotensin with Dowex $50 \mathrm{~W}-\mathrm{X} 4\left(\mathrm{H}^{+}\right)$column chromatography, and bioassay on rat blood pressure. The recovery rate of added synthetic angiotensin II was $92.0 \pm 5.3 \%$ (S.D.). Plasma renin activity in 30 normal subjects ranged from 3.0 to $17.0 \mathrm{ng}$ angiotensin equivalent per $\mathrm{ml}$ plasma. These values were significantly elevated in 6 cases of renovascular hypertension $(20-84 \mathrm{ng} / \mathrm{ml})$, in a case of interruption of the aorta $(35 \mathrm{ng} / \mathrm{ml})$, and in a case of malignant hypertension $(80 \mathrm{ng} / \mathrm{ml})$, while in 3 cases of primary aldosteronism they were suppressed to subnormal levels $(2.0-2.3 \mathrm{ng} / \mathrm{ml})$.
\end{abstract}

The present method is easily applicable in ordinary elinical laboratories.

The renin-angiotensin system has become very important in the study of hypertensive diseases, not only from the academic point of view, but also from the practical standpoint of diagnosis and treatment. Estimation of plasma renin activity (PRA) is one of the most useful laboratory techniques for the diagnosis of such diseases as primary aldosteronism, ${ }^{1}$ renovascular hypertension, ${ }^{2}$ reninproducing tumor, ${ }^{3,4}$ malignant hypertension ${ }^{5}$ and other secondary aldosteronisms. ${ }^{6}$

Various methods hitherto devised by previous authors for the determination of PRA are too complicated in their procedures to be utilized in daily laboratory practice or are not sensitive enough for some clinical purposes.

In the present study, we have tried to establish a practical and sensitive method for the estimation of PRA with less complicated procedures. The method consists of incubation of human plasma with small amounts of ethylenediamine tetraacetic acid (EDTA) and disopropyl-fluorophosphate (DFP), partial purification using Dowex $50 \mathrm{~W}-\mathrm{X} 4\left(\mathrm{H}^{+}\right)$column chromatography and bioassay on rat blood pressure. 


\section{Materials and Methods}

Preparation of blood samples

Peripheral venous blood was drawn from a cubital vein or elsewhere into a syringe moistened with heparin as an anticoagulant, and immediately centrifuged at 3,000 rpm for $15 \mathrm{~min}$ at room temperature. The plasma, when not immediately submitted to measurement, was transferred into a stoppered tube and stored frozen until use. No plasma sample was stored longer than 3 weeks, during which no detectable decrease in renin activity was observed.

The plasma (usually 2.0-3.0 ml) was pipetted into a centrifuge tube containing onetenth the volume $(0.2-0.3 \mathrm{ml}$, corresponding to the plasma volume) of $1 \mathrm{M}$ acetate buffer, $\mathrm{pH}$ 5.5 , one-twentieth the volume of $6.7 \%$ EDTA in physiological saline (pH 5.5), 2-3 drops (1:100 volume) of $5 \%$ DFP in isopropyl alcohol, and one drop of $5 \%$ Dextromycine (used as a bacteriostatic agent). This mixture was carefully adjusted to $\mathrm{pH} 5.5$ with $1-2 \mathrm{~N} \mathrm{HCl}$ and was incubated in a water bath at $37.5^{\circ} \mathrm{C}$ for 16 hours without shaking. The purpose of adding both EDTA and DFP into the incubation mixture was to inhibit angiotensinase activities in the plasma.?

\section{Extraction and purification}

At the end of incubation, two volumes (usually $4.0-6.0 \mathrm{ml}$, corresponding to the starting plasma volume) of physiological saline were added to the incubation mixture and its $\mathrm{pH}$ was adjusted again to 5.5. The sample was then heated in a boiling water bath for 5-10 min, cooled and centrifuged at 3,000 rpm for $10-15 \mathrm{~min}$. The supernatant was transferred to another vessel, and the precipitate was washed with equal volume $(2.0-3.0 \mathrm{ml})$ of physiological saline and the mixture was centrifuged to collect the supernatant. The last precipitate was discarded.

The collected supernatant was adjusted to $\mathrm{pH} 1.0-1.5$ with $1-2 \mathrm{~N} \mathrm{HCl}$, and was applied on a column $(0.6 \times 2.5 \mathrm{~cm})$ of Dowex $50 \mathrm{~W}-\mathrm{X}_{4}\left(200-400 \mathrm{mesh}, \mathrm{H}^{+}\right.$. form $)$at room temperature. The column was washed with $0.2 \mathrm{M}$ acetate buffer $(\mathrm{pH}$ 6.0) until the $\mathrm{pH}$ of the effluent reached 6.0. Then the column was washed with $3.0 \mathrm{ml}$ of the distilled water. These effuents were discarded.

Finally, angiotensin was eluted from the column with $3.0 \mathrm{ml}$ of $0.1 \mathrm{~N} \mathrm{NaOH}$ into a small graduated tube contrining two drops of $2 \mathrm{~N} \mathrm{HCl}$ and one drop of $0.05 \%$ bromthymol blue (BTB) as a $\mathrm{pH}$ indicator. The eluate was immediately adjusted to approximately pH 7.ก.

After the final volume had been recorded, the neutralized eluate was stored in a deepfreezer until the bioassay.

\section{Biontasay}

Albino rats of Wistar strain, both sexes, weighing $100-200 \mathrm{~g}$, were used as test animals. They were anesthetized with sodium pentobarbital $(4 \mathrm{mg} / 100 \mathrm{~g}$ of body weight, intraperitoneally). Fluctuation of blood pressure was minimized with hexamethonium ( $2 \mathrm{mg} / 100 \mathrm{~g}$ of body weight, subcutaneously). Atropine sulfate was administered to inhibit bronchial secretions $(0.05 \mathrm{mg} / 100 \mathrm{~g}$ of body weight, intraperitoneally). The trachea was cannulated to stabilize the breathing of the rat. Small cannula was inserted into the right carotid artery, and was connected with an electrical manometer equipped with a pen-writing recorder. Injections were given through another cannulation into the right femoral vein in doses of 0.1 to $0.3 \mathrm{ml}$ using a tuberculin syringe.

The quantity of angiotensin in the sample was assayed by comparing its pressor effect with that of synthetic stanlard (valyl-5-angiotensin II aspartyl- $\beta$-amide, 'Hypertensin', Ciba). When angiotensin was present in the samples in amounts of less than $2.0 \mathrm{ng} / \mathrm{ml}$, the accuracy of assay was questionable, and the values were described as 'trace'. 
Results and Comments on the Method

Effects of $p H, E D T A$ and DFP on renin reaction in human plasma

Angiotensin production and inhibition of angiotensinase activity during the incubation at $37.5^{\circ} \mathrm{C}$ for 16 hours were studied at various $\mathrm{pHs}$. In one series, EDTA alone was added, and in the other both EDTA and DFP were used as an angiotensinase inhibitors. The buffer solutions used for $\mathrm{pH}$ adjustment of samples were $1 \mathrm{M}$ acetate buffer for $\mathrm{pH} 4.5-6.5$, and $1 \mathrm{M}$ phosphate buffer for $\mathrm{pH}$ 6.5-7.4, one-tenth volume of each being added to the plasma sample. These incubation mixtures were finally adjusted to respective $\mathrm{pHs}$ with $1-2 \mathrm{~N} \mathrm{HCl}$.

\section{1) Angiotensin production}

Maximal production of angiotensin was found when the sample was incubated with both EDTA and DFP at pH 5.5. Minor differences between the duplicate experiments were observed at $\mathrm{pH} 4.5,6.5$, and 7.4 , but the optimal $\mathrm{pH}$ for the reaction was 5.5 in either series (Fig. 1).

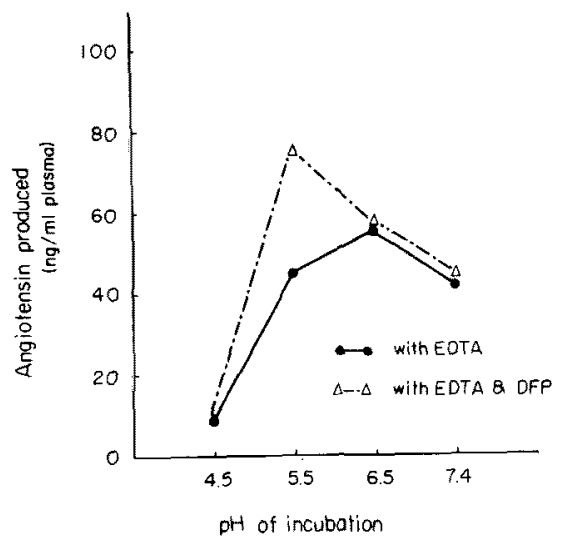

Fig. 1. Effects of $\mathrm{pH}$, EDTA and DFP on the angiotensin production.

The ordinate represents amounts of produced angiotensin, when the plasma $(2.0 \mathrm{ml})$ was incubated with EDTA alone or with both EDTA and DFP, at various pHs (abscissa), at $37.5^{\circ} \mathrm{C}$ for 16 hours.

\section{2) Inhibition of angiotensinase activity}

Inhibitory effects of pH, EDTA and DFP against the angiotensinase activity were studied from the recovery rate of Hypertensin (25 $\mathrm{ng} / \mathrm{ml}$ plasma), which had been added to the plasma at the beginning of the incubation. The recovery rates of added Hypertensin in the samples containing EDTA alone were 44, 60, 78 and $72 \%$ at $\mathrm{pH} 4.5,5.5,6.5$ and 7.4 , respectively. With addition of both EDTA and DFP, the recovery rates increased to $80,96,72$ and $67 \%$ at corresponding $\mathrm{pHs}$.

The angiotensinase activity was inbibited most effectively with addition of both EDTA and DFP at pH 5.5 (Fig. 2). 


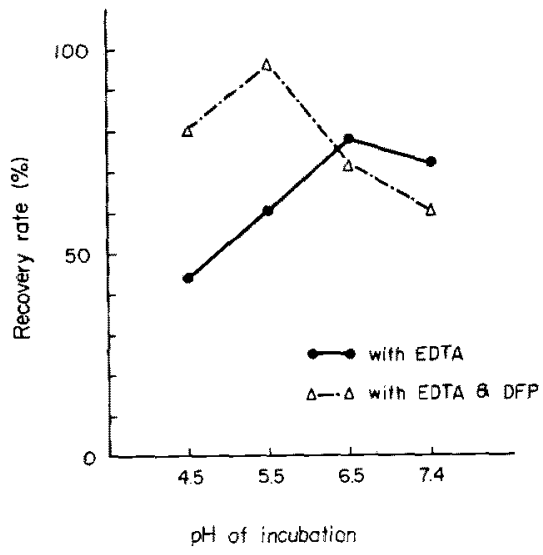

Fig. 2. Effects of $\mathrm{pH}$, EDTA and DFP on the angiotensinase activity.

Hypertensin (10-25 $\mathrm{ng} / \mathrm{ml}$ plasma) was incubated with plasma $(2.0 \mathrm{ml})$, to which either EDTA alone or a combination of EDTA and DFP was added at various $\mathrm{pHs}$ (abscissa), at $37.5^{\circ} \mathrm{C}$ for 16 hours. The ordinate is the recovery rate of added Hypertensin.

\section{Time course of angiotensin production}

The time course of angiotensin yield was studied at various length of incubation time up to 24 hours.

The angiotensin in the incubation mixture increased linearly with time (Fig. 3). The recovery rates of Hypertensin (25 $\mathrm{ng} / \mathrm{ml}$ plasma) added to plasma before incubation were $94.0,92.0$ and $85.4 \%$ at 8,16 , and 24 hours of incubation, respectively (Fig. 4 (A)). On the other hand, when Hypertensin $(10-15 \mathrm{ng} / \mathrm{ml})$ was incubated in physiological saline at $\mathrm{pH} 5.5$, its recovery rates were 95.0 and $87.5 \%$ after 16 and 24 hours of incubation, respectively (Fig. 4(B)). Because of these findings, the small gradual decrements of recovery rates with time might be attributable mostly to the auto-degradation of angiotensin, which was almost negligible up to 16 hours of incubation.

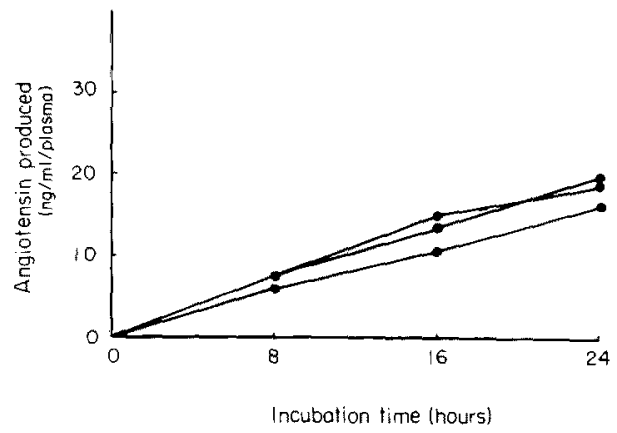

Fig. 3. Time course of argiotensin production.

The plasma $(2.0 \mathrm{ml})$ was incubated with addition of both FDTA and DFP, at $\mathrm{pH} 5.5$ and at $37.5^{\circ} \mathrm{C}$ for $8-24$ hours. The ordinate is the amount of the produced angiotensin, which increases linearly with time (abscissa). 

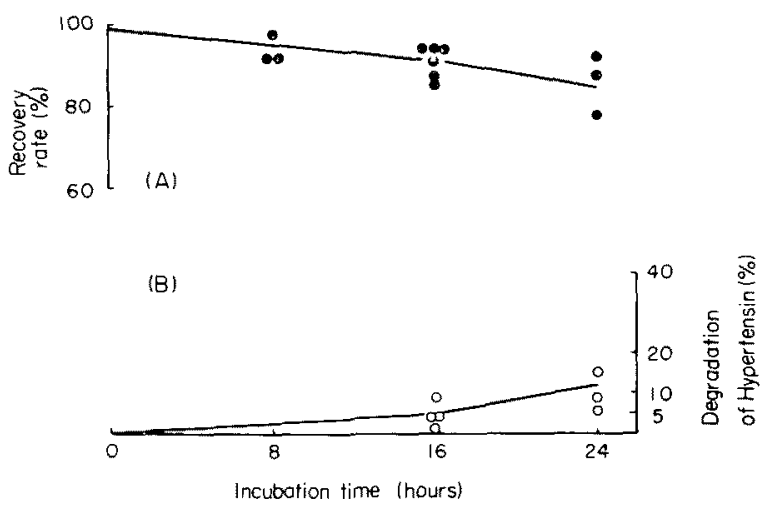

Fig. 4. Time course of recovery rate.

Hypertensin $(20-50 \mathrm{ng})$ added to plasma $(2.0 \mathrm{ml})$ or to physiological saline $(3.0 \mathrm{ml})$ was incubated with addition of both EDTA and DFP at $\mathrm{pH} 5.5$ and at $37.5^{\circ} \mathrm{C}$ for $8-24$ hours. The ordinates are the recovery rate $(A)$ and the auto-degradation rate $(B)$ of added Hypertensin at each incuhation time (abscissa).

From these results, it was considered that the incubation of 16 hours was adequate for the measurement of PRA.

\section{Recovery rate}

\section{1) Recovery rate of extraction-purification procedure}

When known amounts of Hypertensin (50-100 ng) were added to the plasma just before extraction, they were almost quantitatively recovered by the present method (recovery rate, $99-100 \%$; mean 104\%) (Table 1).

TABLE 1. Recovery rate of extraction-purification procedure in recovery experiment $(A)$

\begin{tabular}{c|c|c|c}
\hline $\begin{array}{c}\text { Plasma } \\
(\mathrm{ml})\end{array}$ & $\begin{array}{c}\text { Hypertensin } \\
\text { added } \\
(\mathrm{ng})\end{array}$ & $\begin{array}{c}\text { Total Hypertensin } \\
\text { in fol eluate } \\
(\mathrm{ng})\end{array}$ & $\begin{array}{c}\text { Recovery rate } \\
(\%)\end{array}$ \\
\hline 2.0 & 100 & 99 & \\
2.0 & 100 & 105 & 99 \\
2.0 & 50 & 54 & 105 \\
2.0 & 50 & 51 & 108 \\
2.0 & - & 0 & - \\
2.0 & - & 0 & - \\
& & Mean recovery rate & 104
\end{tabular}

* Synthetic angiotensin II (Hypertensin) was added to the plasma immediately before the extraction-purification procedure.

\section{2) Recovery rate of whole procedure}

The recovery rates through the whole procedure, when studied by addition of Hypertensin $(50 \mathrm{ng})$ to the plasma $(2.0 \mathrm{ml})$ from 6 patients before incubation were $84-98 \%$, the mean and standard deviation being $92.0 \pm 5.3 \%$ (Table 2 ). 
TaBLe 2. Recovery rates of the whole procedure in recovery experiment ( $B$ )

\begin{tabular}{|c|c|c|c|c|}
\hline \multicolumn{2}{|c|}{$\begin{array}{l}\text { No. of } \\
\text { subjects }\end{array}$} & $\begin{array}{l}\text { Hypertensin } \\
\text { added } \\
\text { (ng) }\end{array}$ & $\begin{array}{c}\text { Total angiotensin }(T) \\
\text { in final eluate } \\
(\mathrm{ng})\end{array}$ & $\begin{array}{c}\text { Recovery rate } \\
\left(\frac{\mathrm{Tb}-\mathrm{Ta}}{50} \times 100\right)(\%)\end{array}$ \\
\hline \multirow{3}{*}{1} & a & None & 35.0 & \\
\hline & $\mathrm{b}$ & 50 & 84.0 & 98 \\
\hline & a & None & 9.0 & \\
\hline 2 & $\mathrm{~b}$ & 50 & 51.0 & 84 \\
\hline \multirow{2}{*}{3} & a & None & 12.0 & \\
\hline & b & 50 & 60.0 & 96 \\
\hline \multirow{2}{*}{4} & a. & None & 8.0 & \\
\hline & $\mathrm{b}$ & 50 & 51.0 & 86 \\
\hline \multirow{2}{*}{5} & a & None & 26.0 & \\
\hline & b & 50 & 72.0 & 92 \\
\hline \multirow{3}{*}{6} & $\mathrm{a}$ & None & 150.0 & \\
\hline & b & 50 & 198.0 & 96 \\
\hline & & & Mean recovery rate \pm SD & $92.0 \pm 5.3 \%$ \\
\hline
\end{tabular}

\section{Reproducibility}

Table 3 shows the results of 5 repeated measurements on the same plasma sample. Estimated values ranged from 15.3 to $17.3 \mathrm{ng} / \mathrm{ml}$ plasma (mean, $16.4 \pm$ $0.66(\mathrm{sD}) \mathrm{ng} / \mathrm{ml}$ ), hence the present method was considered to ensure enough reproducibility.

TABLE 3. Reproducibility of the results

\begin{tabular}{c|c}
\hline $\begin{array}{c}\text { No. of } \\
\text { experiments }\end{array}$ & $\begin{array}{c}\text { Angiotensin produced } \\
(\mathrm{ng} / \mathrm{ml} \text { plasma) }\end{array}$ \\
\hline 1 & 16.7 \\
2 & 15.3 \\
3 & 16.0 \\
4 & 16.5 \\
5 & 17.3 \\
Maen \pm SD & $16.4 \pm 0.66$
\end{tabular}

\section{Specificity}

The pressor substance estimated by the present method was thermostable and was easily destroyed by incubation with chymotrypsin. The optimal pH and the effects of both EDTA and DFP on its production were quite similar to those reported by Pickens and his associates, ${ }^{7}$ or by Helmer and Judson. ${ }^{8}$ It gave the same response curves in rat blood pressure as synthetic angiotensin II.

When $100 \mu \mathrm{g}$ of noradrenaline were added to the plasma after incubation, its $3.3 \%$ were recovered through purification procedure. But the pressor effect of catecholamine was negligible when it was added before incubation in the same dosage of $100 \mu \mathrm{g}$, indicating unstability of the amine during this procedure. From this result, the present method is free from contamination of adrenergic amines, even when it is applied to patients with pheochromocytoma.

Another pressor substance, discovered by Arneil and Dekanski ${ }^{9}$ in 1954 and later 
characterized by Khairallah and Page, ${ }^{10}$ is produced in plasma when it is incubated for prolonged periods (4-36 hours) at $37^{\circ} \mathrm{C}$ at natural $\mathrm{pH}$. This substance was not recovered by the resin chromatography in the present method.

When tested on the isolated rat uterus, some bradykinin-like activity was detected in the incubated plasma, the amount being about $30 \mathrm{ng}$ bradykinin eq./ml plasma. In addition, $10 \mu \mathrm{g}$ of synthetic bradykinin added to the plasma almost resisted the prolonged incubation quantitatively (94\%). This was conceivable in the light of the presence of EDTA and acidic $\mathrm{pH}$ during incubation. However; the recovery rate of $5-10 \mu \mathrm{g}$ of bradykinin on the Dowex column chromatography was found to be only $1-4 \%$ of applied doses, and the eluate from the column had no effect on rat blood pressure. When the final extract from the human plasma was tested for the presence of bradykinin on rat uterus preparation, no response was elicited. Therefore, it was considered that the contamination of bradykinin was eliminated in the present method.

From these results, it seems very likely that the pressor substance estimated by the present method was identical with angiotensin.

\section{Renin activity in various hypertensions and normal controls}

PRA was estimated in normal adults and in various hypertensive patients. The results obtained are shown in Fig. 5, in which PRA was expressed in terms of angiotensin formed by renin during the incubation ( $\mathrm{ng} / \mathrm{ml}$ plasma). Blood samples were obtained in the early morning from fasting-recumbent subjects, who were fed on restricted diet with no special medications which might have influence on body water or electrolyte balance.

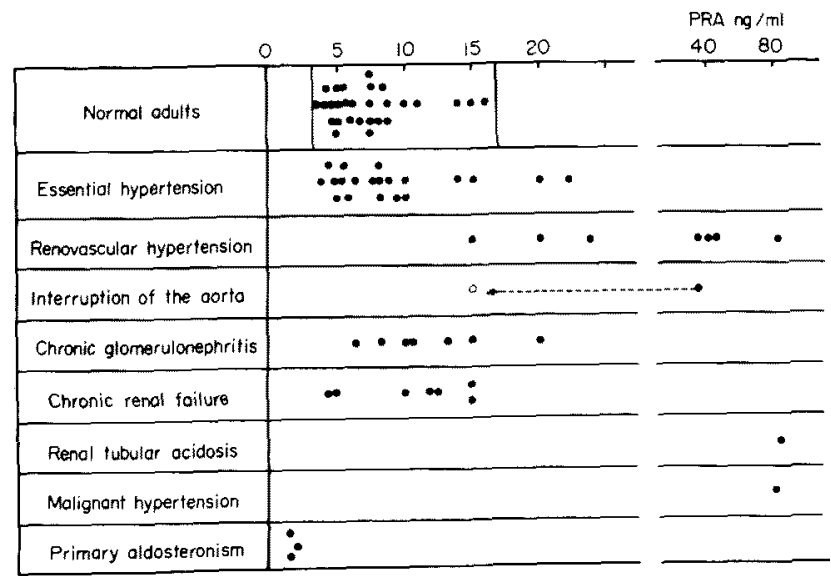

Fig. 5. Plasma renin activity in various hypertensions and normal controls.

Thirty normal subjects were examined as controls. The results were as follows: normal range was $3.0-17.0 \mathrm{ng} / \mathrm{ml}$ plasma; mean value was $7.9 \pm 4.7$ (sD) $\mathrm{ng} / \mathrm{ml}$. 
PRA in 21 cases of essential hypertension was estimated; in 19 of them, the values were within normal range $(3.5-15 \mathrm{ng} / \mathrm{ml}$, mean $7.5 \mathrm{ng} / \mathrm{ml})$, and in the remaining two, slightly elevated (20, and $22 \mathrm{ng} / \mathrm{ml})$.

In 7 cases of renovascular hypertension, PRA was elevated to $20-84 \mathrm{ng} / \mathrm{ml}$ in 6 cases with unilateral renal artery stenosis, but in another case with bilateral stenosis, the value was within normal range $(15 \mathrm{ng} / \mathrm{mll})$.

In a case of interruption of the descending aorta, the value was elevated to $35.0 \mathrm{ng} / \mathrm{ml}$, which returmed to normal $(15 \mathrm{ng} / \mathrm{ml})$ after the surgical correction.

In 7 cases of chronic glomerulonephritis and in 7 cases of chronic renal failure with hypertension, PRA was almost within normal range, while in such cases as renal tubular acidosis, renal rickets and malignant hypertension, PRA was found to be variously elevated $(84,18$ and $80 \mathrm{ng} / \mathrm{ml}$, respectively).

In contrast, PRA in 3 cases of primary aldosteronism was suppressed to subnormal levels $(2.0,2.0$, and $2.3 \mathrm{ng} / \mathrm{ml}$, respectively; mean, $2.1 \mathrm{ng} / \mathrm{ml})$.

\section{Discussion}

Although the direct estimation of renin concentration in human plasma has been tried with the technique of radioimmunoassay, ${ }^{11,12}$ it is a current tendency to determine PRA indirectly with bioassay of angiotensin formed by the enzymatic action of renin in vitro.

In the latter method, it is most important to inactivate angiotensinases. It has been known that human plasma contains two angiotensinase activities, one having the optimal $\mathrm{pH}$ at 7.5 and the other at $4.5 .^{2,13}$

Helmer and Judson ${ }^{8}$ adjusted the $\mathrm{pH}$ of incubation mixture to 5.5 , at which $\mathrm{pH}$ angiotensinase activity was minimal and the renin activity was maximal. In their method, however, the recovery rate was only $30-50 \%$.

Brown and his coworkers ${ }^{14}$ offered another method, in which both renin and substrate were completely purified and were incubated under the enzymologically optimal condition. This method was too complicated in procedures and too poor in recovery rate $(30 \%)$ to be used for routine clinical measurement.

Boucher et $a l .{ }^{15}$ found Dowex resin $50 \mathrm{~W}-\mathrm{X} 2\left(\mathrm{NH}_{4}^{+}\right)$to be most suitable for protecting angiotensin from angiotensinase during the incubation. This method has a relatively high recovery rate (mean, 87\%). Gould et al. ${ }^{16}$ pointed out that the presence of Dowex resin in the incubation mixture might influence the hydrolysis of renin substrate.

Skinner ${ }^{17}$ and Gould et al. ${ }^{16}$ proposed other methods, in which plasma was dialyzed against EDTA solution to inactivate the angiotensinases. By their methods, the recovery rate was higher than $80 \%$. In our experiment, when the plasma was dialyzed against $0.003 \mathrm{M}$ EDTA overnight and incubated at $\mathrm{pH} 7.4$ for 16 hours, the recovery rate of Hypertensin added before incubation ranged from 70 to $80 \%$.

Pickens et al. ${ }^{7}$ found that the angiotensinase activity with optimal $\mathrm{pH}$ at 7.5 could be inactivated by dialyzing against EDTA, and that another enzyme activity 
with optimal $\mathrm{pH}$ at 4.5 could be inactivated by DFP. By combined use of these inhibitors, they could elevate the recovery rate to $85 \pm 7 \%$. Because EDTA is toxic or sometimes lethal to rats when it is injected intravenously, it must be dialyzed away from the plasma before incubation. This time-consuming dialysis was made unnecessary in the present method by the simple chromatography on Dowex resin. The dose of DFP is so small that it is not harmful to rats, even if it remains after purification.

The velocity of angiotensin formation is influenced by the amount of substrate (angiotensinogen) quantitatively according to the kinetics of renin reaction. ${ }^{16,17}$ It is desirable for the estimation of PRA that a large amount of substrate exists in the reaction system to carry the hydrolysis by renin with a zero-order reaction kinetics. Human plasma contains $600-1,200 \mathrm{ng}$ angiotensin equivalents of substrate per $\mathrm{ml}$ except some cases with liver cirrhosis in which considerable reduction in renin substrate has been reported. ${ }^{16}$ This is considered sufficient in usual circumstances, but when renin concentration is excessively elevated, the renin reaction may shift to the first-order. Under these conditions, addition of renin substrate, especially of human species, may be necessary for the reaction to be zeroorder. A further investigation about these problems is in progress.

In measuring PRA in elinical practice, it is desired that the volume of plasma sample is so small that no discomfort is caused in patients, and the estimations can be carried out repeatedly. Actually, with several methods previously published, ${ }^{16,18}$ it is possible to determine PRA by prolonged incubation of small amount of plasma. In these methods including the present one, the addition of antibiotics may be necessary to avoid the influence of bacteria.

It has been reported that vasopressor Arneil factor was not adsorbed on the Dowex resin. ${ }^{15}$ This has been verified in the present investigation. Catecholamines had no influence in this method.

In the present method, both EDTA and DFP were added directly to the incubation mixture to omit the long time dialysis. The angiotensinase activities could be abolished so completely that the recovery rate attained $92.0 \pm 5.3 \%$. The volume of plasma sample needed for the assay was only $2.0-3.0 \mathrm{ml}$. Through a simple procedure of Dowex resin column chromatography, the angiotensin was partially purified, and both EDTA and DFP were eliminated so completely that the eluate could be directly assayed on rat blood pressure. The concentration of the electrolyte in the final eluate was suitable to bioassay.

Accurate estimation of lowered levels of PRA is most valuable for the diagnosis of primary aldosteronism as previously reported. ${ }^{1}$ In the present study, we could confirm that PRA in 3 cases of primary aldosteronism was suppressed to a subnormal level.

Elevation and suppression of PRA in various patients could be readily detected by the present method. 


\section{Acknowledgment}

I am greatly indebted to Prof. T. Torikai for his leadership and to Assoc. Prof. K. Yoshinaga and Dr. T. Sato for their advice throughout this study.

\section{References}

1) Conn, J.W., Rovner, D.R. \& Cohen, E.L. Normal and altered function of the reninangiotensin-aldosterone system in man. Ann. intern. Med., 1965, 63, 266-284.

2) Winer, B.M., Lubbe, W.F., Simon, M. \& Williams, J.A. Renin in the diagnosis of renovascular hypertension. J. Amer. med. Ass., 1967, 202, 121-128.

3) Robertson, P.W., Klidjian, A., Harding, L.K., Walters, G., Lee, M.R. \& Robb-Smith, A.H.T. Hypertension due to a renin-secreting renal tumour. Amer. J. Med., 1967, 43, 963-976.

4) Kihara, T. A case of renin producing renal tumor: Advocation of juxtaglomerular

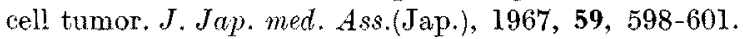

5) Maebashi, M. Estimation of circulating renin under various clinical conditions. Jap. Circulat. J. (Jap.), 1964, 28, 778-785.

6) Yoshinaga, K., Aida, M., Maebashi, M., Sato, T., Abe, K. \& Miwa, I. Assay of renin in peripheral blood: A modification of Helmer's method for the estimation of circulating renin. Tohok $J$, exp. Med., 1963, 80, 32-41.

7) Pickens, P.T., Bumpus, F.M., Lloyd, A.M., Smeby, R. R. \& Page, I.H. Measurement of renin activity in human plasma. Circulat. Res., 1965, 17, 438-448.

8) Helmer, O.M. \& Judson, W.E. The quantitative determination of renin in the plasma of patients with arterial hypertension. Circulation, 1963, 27, 1050-1060.

9) Arneil, G.C. \& Dekanski, J.B. Excess of vasopressor activity in plasma of nephritic children with hypertension. Lancet, 1954, 2, 1204-1207.

10) Khairallah, P.A. \& Page, I.H. A vasopressor lipid in incubated plasma. Amer.J. Physiol., 1960, 199, 341-345.

11) Vallotton, M.B., Page, L.B. \& Haber, E. Radioimmunoassay of angiotensin in human plasma. Nature, 1967, 215, 71t-715.

12) Fukuchi, S. Renin and angiotensin. Igaku no Ayumi (Jap.), 1968, 67, 470-476.

13) Khairallah, P.A., Bumpus, F.M., Page, I.H. \& Smeby, R.R. Angiotensinase with a high degree of specificity in plasma and red cells. Science, 1963, 140, 672-674.

14) Brown, J.J., Davies, D.L., Lever, A.F., Robertson, J.I.S. \& Tree, M. The estimation of renin in human plasma. Biochem. J., 1964, 93, 594-600.

15) Boucher, R., Veyrat, R., de Champlain, J.\& Genest, J. New procedures for measurement of human plasma angiotensin and renin activity levels. Canad. med. Ass. J., 1964, 90, 194-201.

16) Gould, A.B., Skeggs, L.T. \& Kahn, J.R. Measurement of renin and substrate concentrations in human serum. Lab. Invest., 1966, 15, 1802-1813.

17) Skinner, S.L. Improved assay methods for renin 'concentration' and 'activity in human plasma. Circulat. Res., 1967, 20, 391-402.

18) Nakamura, M., Arakawa, K. \& Minohara, A. Improved method for estimation of plasma renin activity. J. Jap. Soc. intern. Med. (Jap.), 1967, 56, 905-906. 